\title{
Wave onset in central gray matter - its intrinsic optical signal and phase transitions in extracellular polymers
}

\author{
VERA M. FERNANDES-DE-LIMA ${ }^{1}$, JOÃO E. KOGLER ${ }^{1}$, JOCELYN BENNATON ${ }^{2}$ \\ and WOLFGANG HANKE ${ }^{3}$ \\ ${ }^{1}$ LSI - Laboratory of Integrated Systems, EPUSP - Escola Politécnica da Universidade de São Paulo \\ 05508-900, São Paulo, SP, Brazil \\ ${ }^{2}$ Department of Electronic Systems EPUSP \\ ${ }^{3}$ Membrane Biophysics Division, Hohenheim University, Germany \\ Manuscript received on November 14, 2000; accepted for publication on May 16, 2001; \\ presented by LENY A. CAVAlCANTE
}

\begin{abstract}
The brain is an excitable media in which excitation waves propagate at several scales of time and space. " Onedimensional" action potentials (millisecond scale) along the axon membrane, and spreading depression waves (seconds to minutes) at the three dimensions of the gray matter neuropil (complex of interacting membranes) are examples of excitation waves. In the retina, excitation waves have a prominent intrinsic optical signal (IOS). This optical signal is created by light scatter and has different components at the red and blue end of the spectrum. We could observe the wave onset in the retina, and measure the optical changes at the critical transition from quiescence to propagating wave. The results demonstrated the presence of fluctuations preceding propagation and suggested a phase transition. We have interpreted these results based on an extrapolation from Tasaki's experiments with action potentials and volume phase transitions of polymers. Thus, the scatter of red light appeared to be a volume phase transition in the extracellular matrix that was caused by the interactions between the cellular membrane cell coat and the extracellular sugar and protein complexes. If this hypothesis were correct, then forcing extracellular current flow should create a similar signal in another tissue, provided that this tissue was also transparent to light and with a similarly narrow extracellular space. This control tissue exists and it is the crystalline lens. We performed the experiments and confirmed the optical changes. Phase transitions in the extracellular polymers could be an important part of the long-range correlations found during wave propagation in central nervous tissue.
\end{abstract}

Key words: intrinsic optic signals, volume phase transitions, polymers, spreading depression, central gray matter, extracellular matrix.

\section{INTRODUCTION}

Spreading depression (SD) waves in the brain are an example of self-organized waves in excitable media. Bures and collaborators (Bures et al. 1984) were the first to point out the similarities between the

Correspondence to: Dr. Vera Maura Fernandes de Lima

E-mail: vmaura@lac.usp.br
SD waves and reaction-diffusion chemical waves. Both of them annihilate on collision, and both can circulate around obstacles. Also, repetitive waves are generated from a leading center in both systems. Based on these similarities, Bures predicted and demonstrated experimentally in the most accessible part of the central gray matter, the neural retina, the existence of self-sustained spreading depression 
spiral waves (Goroleva and Bures 1983).

The demonstration was possible in the isolated chicken retina because, in the retina, SD waves are accompanied by marked changes in the optical properties of the tissue, the so-called intrinsic optical signal or IOS. This prominent intrinsic optical signal allows a complete two-dimensional view of the phenomenon that can be seen with naked eye (Gouras 1958, Martins-Ferreira and Oliveira-Castro 1966). The intrinsic optical signal (IOS) that is concomitant with retinal spreading depressions (RSDs) is a complex phenomenon. It enwraps several components of increased scatter of light by the tissue that begins hundreds of milliseconds after a stimulus and continues for 20 to 30 minutes in a complex sequence of events (for a recent review on the RSDs IOS and all wave concomitants, see Fernandes de Lima and Hanke 1997).

In reaction-diffusion chemical systems and in other self-organized spatiotemporal patterns, including the RSD, fluctuations in the parameters of the systems must precede the self-organized wave propagation (Haken 1977). Although predicted by theorists, the experimental demonstration of the presence of such fluctuations and their amplification at the critical self-organization transition is very difficult in most natural systems because of the time/ space scales of these events. In previous experiments, we could see that: 1. A temporal delay existed between the stimulation of the system and the onset of propagation (Fernandes de Lima and Hanke 1996, Brand and Hanke 1996); 2. Fluctuations in the red scatter preceded the wave in space (Fernandes de Lima et al. 1994); 3. A spatial displacement of wave onset due to mechanical stimulation was possible, due to long range interactions (Fernandes de Lima and Hanke 1996). All these observations are in accord with the presence and possible amplification of fluctuations in the system at the critical transition. One indirect evidence of the predicted fluctuations is that amplification could be observed in collision experiments through the acceleration of the propagation velocity of the colliding waves (Goldermann et al. 1998).
In this paper, we show in detail the space/time evolution of the predicted fluctuations that are present in the IOS that preceded the classical increase in light scatter associated with SDs propagation in gray matter.

Furthermore, we believe that the measured parameter (the scattered red component of the IOS of RSDs) in these previous experiments is closely related to the bulk potential changes during SDs (Fernandes de Lima et al. 1994, Fernandes de Lima and Hanke 1997) permitting an indirect visualization of membrane events in the tissue. This scatter is a macroscopic concomitant, obviously at a suprasynaptic scale of organization. This early component of the IOS, and all the other concomitants of the waves, is maximal at the inner plexiform layer of the retina (Martins-Ferreira and Oliveira-Castro 1971). This layer is $100 \mu \mathrm{m}$ thick and is made of synaptic terminals of the inner retinal neurons and fine processes of just one type of glial cell, the Müller cell. Only $10 \%$ of the total volume is the so-called extracellular "space". This convoluted, so-called "space" is filled with a gel made of anionic biopolyelectrolytes associated with membrane receptors for these extracellular components, also called perineuronal net (Celio et al. 1998). The membrane receptors are made of sugar and protein complexes (glycoproteins) in which negatively charged groups protrude at the external surface of the membranes. The fixed charges of this perineuronal net and membrane surfaces bind counterions and water to maintain electroneutrality.

Extracellular matrix complexes and artificial anionic gels share some common features in the way they associate with water. A small quantity expands with water to occupy a large volume. And changes of $\mathrm{pH}$, ionic or osmotic conditions, can drastically alter their conformation. When continuous and small changes in the environment promote drastic volume changes, it is said that the gel suffered a volume phase transition (see Tasaki and Byrne 1992 and 1994).

We have been leaded to the following hypothesis: the optical changes that we see before wave 
propagation, and at the wavefront, are due to volume phase transitions in the matrix filling the extracellular space in the inner plexiform layer. First, the optical signal is a macroscopic event and so are the bulk phase volume transitions of ionic polymer gels (e.g., Kokufuta and Matsukawa 1996 and Inoue et al. 1997). Second, these volume phase transition can be self-organized: self-oscillating swelling and deswelling of polymer gels have been described (Yoshida et al. 1995). Coupling $\mathrm{pH}$ and temperature sensitive gels to non-linear chemical reactions in the external media created the self-organized oscillatory behavior. Accordingly, during SDs, marked changes in the extracellular ionic environment do take place.

In order to verify the hypothesis about the origin of the early increase in scattered light in RSDs, we show, in this paper, the results of additional experiments designed to demonstrate that extracellular current flow changes the optical properties of transparent tissue. We have reasoned that, if the red scatter was due to volume phase transitions in the interactions of the membrane cell coat and the extracellular matrix, as a consequence of ions movement across membranes, then it had to be present when a current flow was forced in the extracellular space, within a tissue having the following features: 1. A structure similar to the retinal tissue with respect to volume of the extracellular space; 2 . Very close apposition of membranes; and 3. Last but not least, the tissue had to be transparent, in order to allow changes in its optical properties at macroscopic scale (i.e. of the same order of magnitude as the signal observed in the retina). All these features are realized in the crystalline lens; the extracellular space in the lens accounts for only $5 \%$ of the total volume. In this narrow cleft, the water content is the lowest in the body, with $66 \%$ protein and $33 \%$ water (Cotlier 1981). It is possible, then, that all this water is associated water either to the extracellular matrix or to the membrane external surface.

In the second part of this paper we describe a lens preparation from the anterior chamber of chick eyes that we used in experiments designed to test if the forced extracellular current flow would create macroscopic IOSs in the lens.

\section{MATERIAL AND METHODS}

\section{Eye Preparation}

In the experiments, 10-21 days old chicks were killed by decapitation, the eyes were removed immediately, cut at the equator and the separated anterior and posterior compartments put in a Petri dish containing the following nutritive solution: $100 \mathrm{mM}$ $\mathrm{NaCl} ; 6 \mathrm{mM} \mathrm{KCl} ; 1 \mathrm{mM} \mathrm{MgSO} 4 ; 1 \mathrm{mM} \mathrm{CaCl}$; $1 \mathrm{mM}$ NaHPO4; $30 \mathrm{mM}$ NaHCO3; $5 \mathrm{mM}$ TRIS and $30 \mathrm{mM}$ glucose. The $\mathrm{pH}$ was adjusted to 7.4 and the temperature at $30^{\circ} \mathrm{C}$.

\section{Retinal Stimulation}

The RSDs were elicited by a gentle touch with a glass needle (tip diameter less than $50 \mu \mathrm{m}$ ). The glass needle was mounted on a micromanipulator to allow precise positioning and reproducible stimuli.

\section{Crystalline Lens Stimulation}

Isolated lenses were perfused with the same solution as the retinas and impaled with two tungsten electrodes (WPI TM33BO1; with 5 Mohms impedance) that are electrically isolated except for the tip. Square pulses of voltage (from $1 \mathrm{mV}$ to $80 \mathrm{~V}$ and from $.01 \mathrm{msec}$ to 1.5 seconds duration) could be applied to the electrode pair. The stimulus used induced currents at the electrode tip in the order of microampères. For example: a pulse of 20 volts applied in the $5 \mathrm{Mohm}$ electrode tip will give a current of $2.10^{V} / 5.10^{6} \mathrm{~A}$. The electrical stimulation experiments were performed in 5 lenses.

\section{Optical Recordings SetuP}

\section{RETINA EXPERIMENTS}

In Figure 1A the setup for recording of SDs is shown. It consists of a binocular microscope, which is mounted above a stepper-motor driven $\mathrm{X}$ $\mathrm{Y}$ table. On the $\mathrm{X}-\mathrm{Y}$ table, Peltier elements are mounted for temperature control, and on the top of them is a holder for the Petri dish. The perfusion of the solution in the dish is made with a peristaltic 


\section{VIDEO IMAGING SYSTEM}

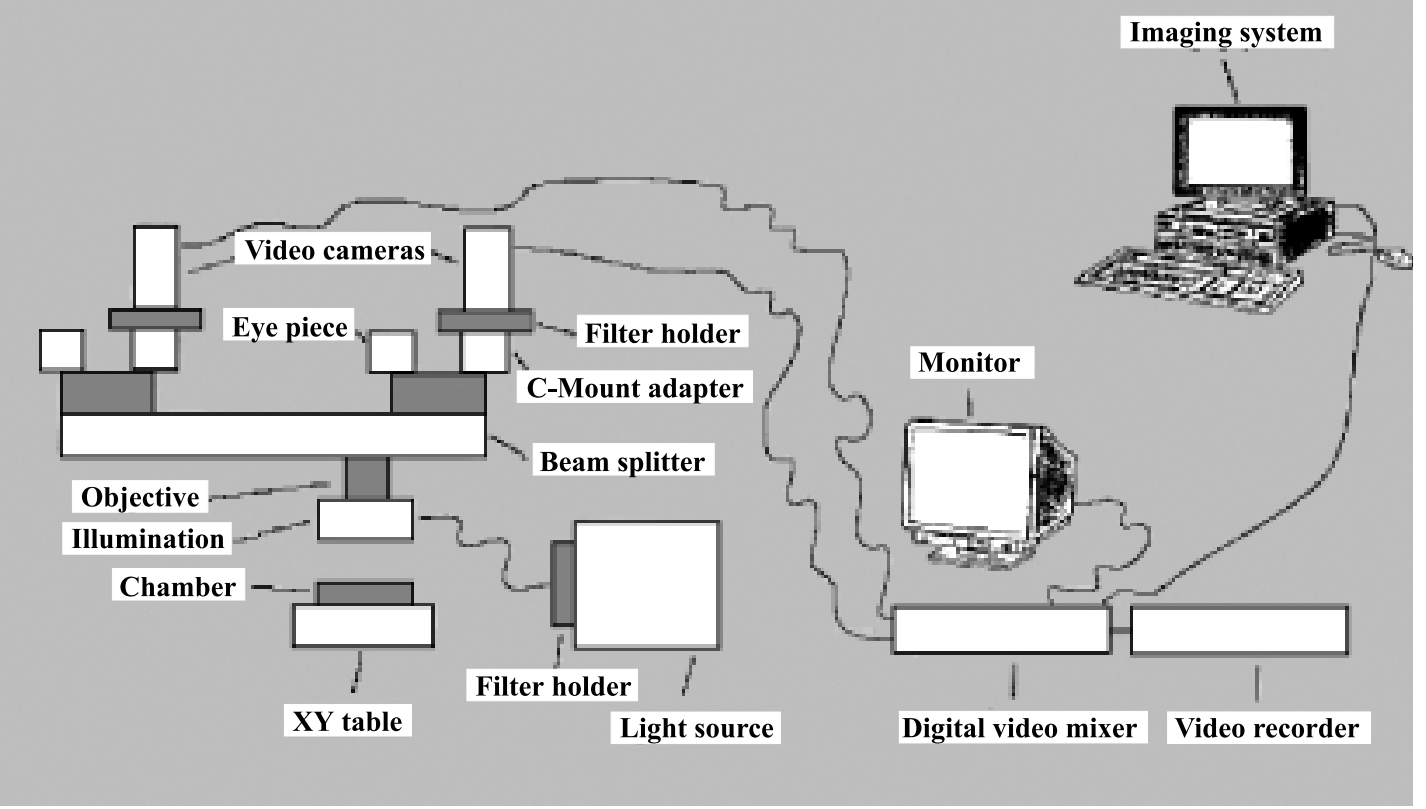

Fig. 1A - Schematic drawing of the experimental setup used for retina videomicroscopy experiments.

pump. In each of the visual pathways of the binocular microscope, beam splitters are mounted which are equipped with $\mathrm{C}$-mount adapters. To these $\mathrm{C}$ mount adapters, a variety of optical recording devices can be mounted. The illumination is made with a $150 \mathrm{~W}$ quartz-halogen lamp through a ringlight. In Figure 1B a propagating wave is shown as seen by the two cameras, each with an optical filter in front. Note that the red scatter signal is brighter at the center or the origin of the wave, i.e. the stimulated region, in the rest of the wave; the blue scatter is stronger and more uniform than the red one. In order to demonstrate the changes in the intrinsic optical signal at the critical transition from quiescence to propagating wave, we recorded the stimulated region with the highest spatial resolution possible in our system (5 microns/pixel) using two cameras (see Figure 1B). In front of each camera, an optical filter was positioned centered at 625 and $425 \mathrm{~nm}$ respectively, with a bandwidth of $20 \mathrm{~nm}$. The total area under each camera was $750 \mu \mathrm{m}^{2}$.

\section{CRYSTALline LENS EXPERIMENTS}

The eye preparation was identical to the retina experiments, except that the crystalline lens were excised from the anterior compartment in six experiments and that this compartment was left intact in another two experiments. The perfusion solution was the same as described above for the retina. The lens were impaled with tungsten electrodes in four experiments (see Figure 5) and illuminated with a low power red laser beam (from a laser pointer) that was focused to the cathode electrode at the center of the lens. In Figure 5 a photo of the lens impaled by the two electrodes is shown with the laser beam positioned in the midpoint between the electrodes, the electrode distance is $1 \mathrm{~mm}$. Note the lens transparency, except at the entering and leaving points of the laser beam. A video camera was mounted in the $\mathrm{C}$-adapter of the binocular microscope and the optical record was stored in videocassettes for offline processing. In three experiments, touching the 
BLUE

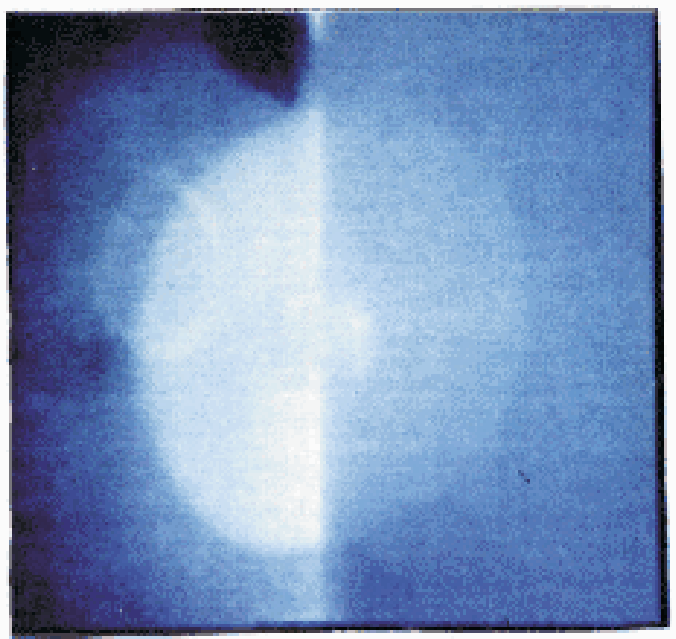

$1 \mathrm{~mm}$

Fig. 1B - Photograph of one propagating retinal spreading depression wave at two wavelengths as recorded in the setup shown in Fig.1A. The photograph shows the simultaneous images from the two cameras. Note the bright spot at the center of the red scattered light image. This region is where the mechanical stimulation was made and it is the origin of the propagated wave.

external capsule of the lens with a glass tube filled with $\mathrm{KCl}$ crystals made the induction of ionic flow. In one experiment, spraying, very gently, the capsule with a $3 \mathrm{M} \mathrm{KCl}$ solution, with a syringe, induced the ionic flow.

\section{RESULTS AND DISCUSSION}

\section{Critical Transition from Quiescence to Propagating Wave}

In Figures $2 \mathrm{~A}$ and $2 \mathrm{~B}$, the mean brightness of all the pixels in the area affected by the stimulus is plotted against time. The measurements were made in 25 frames before the stimulus (one second at the $25 \mathrm{~Hz}$ rate of acquisition) and in one hundred frames following the stimulation (4 seconds), beginning at $600 \mathrm{msec}$ after the touch, (because of optical artifacts from the moving needle). The two plots show that the scatter of red and blue light differ in their be- havior. The mean brightness of the stimulated area increases in the red and in the blue scatter signals. But they differ in their behavior; the mean of the red scatter increases and fluctuates at a higher value immediately after the stimulus. By contrast, in the blue signal, the mean brightness grows in slow ramp faction, and the rate of growth increases in the last second, at the critical transition. In order to show more clearly the trend in the time series of the blue scatter, a line in the figure shows the effect of the application of the moving average technique to the time series of 125 measurements.

In Figures 3 and 4 we show the IOS at the critical transition in space-time plots. These plots were made from the same experiment shown in Figure 2. They were constructed the following way: the brightness of six consecutive frames (about $2 \mathrm{~mm} 2$ total area) were averaged pixel by pixel and them two successive averages were subtracted from each other. The temporal resolution in these difference frames is $240 \mathrm{msec}$. A total of 20 resultant difference frames were obtained from $600 \mathrm{msec}$ to 4.8 seconds after the stimulus, just at the transition to propagation.

The red scatter brightness (Figure 3) fluctuated in time-space, waxing and waning three times before the final amplification at the critical transition. The fluctuations in brightness tend to form rings in the fifth, thirteenth and finally, at the seventeenth difference frames. The sequence of the 19 difference frames is available to the reader in the following address at the Internet: www. Isi.usp.br/ bioinfo/.

The blue scatter signal behavior is shown in Figure 4. In order to see the slow ramp faction of its growth, we made differences from consecutive frames that were 1.5 seconds apart in time. Note that the growth is both in space and in intensity of the differences. Notice also that the process begins discrete in space and that the spatial distribution of scattered light differs in the red and the blue end of spectrum.

The amplification of fluctuations in one of the components of the intrinsic optical signal (IOS) of 


\section{RED SCATTER}

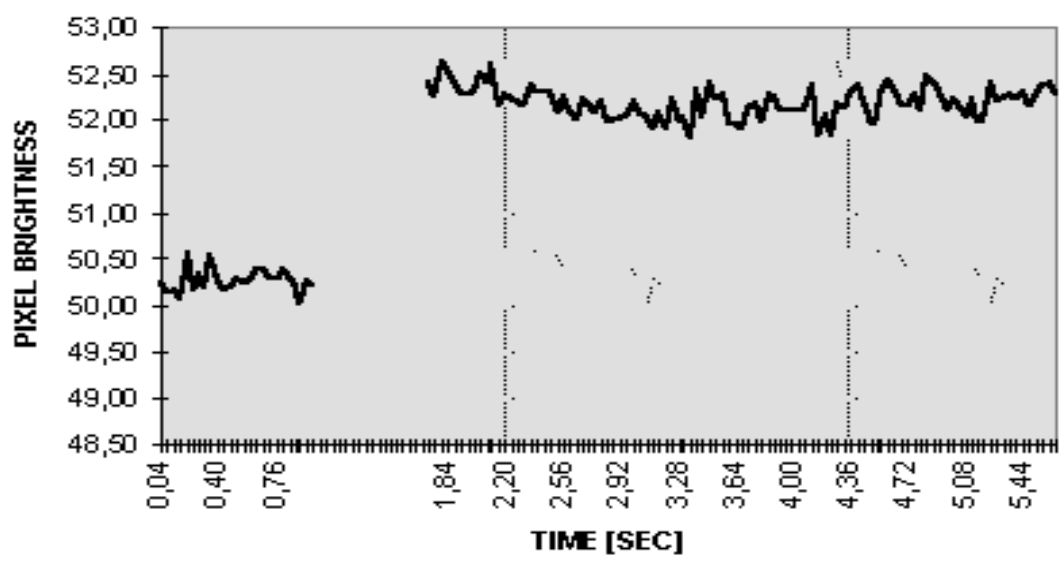

\section{BLUE SCATTER}

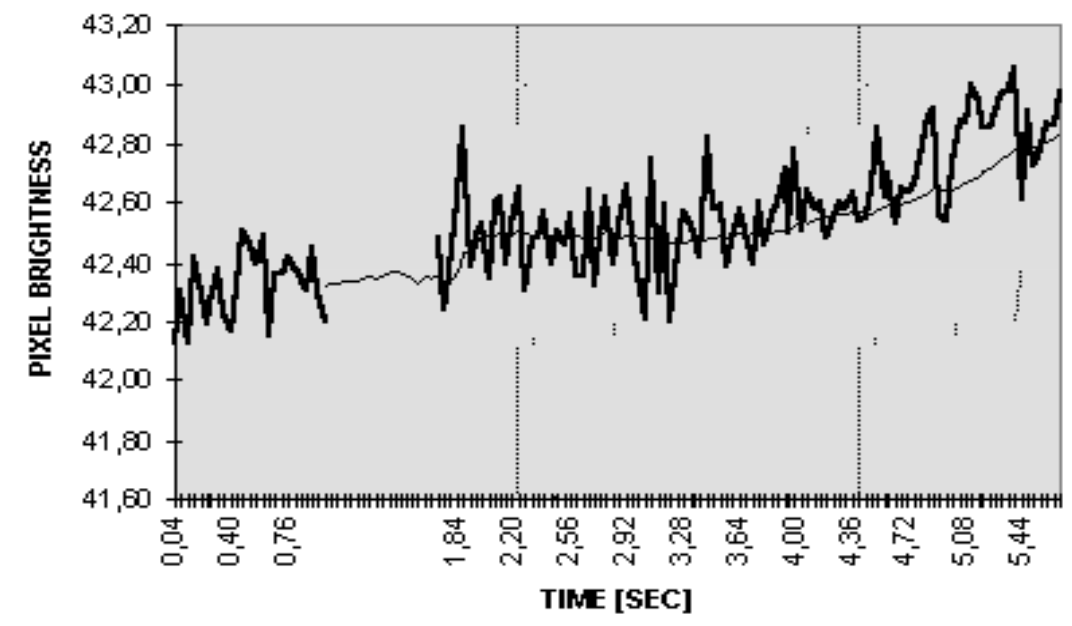

Figs. 2A and B - Mean brightness of a $750 \mu \mathrm{m}^{2}$ area centered at the pixel with the stimulating needle tip and calculated in a 125 frames sequence ( $25 \mathrm{~Hz}$ video acquisition frequency). The sequence begins one second ( 25 frames) before stimulation. The interval corresponds to the first $600 \mathrm{~ms}$ after the stimulus in which there was artifact from the touching and withdrawing needle. After this interval, the mean brightness was calculated in the next 4 seconds terminating just at the transition to propagating wave. In A the mean brightness of the red $(625 \mathrm{~nm})$ scatter is shown. Note the discontinuous, bi-stable behavior. In B the mean brightness of the stimulated area is shown for the blue $(475 \mathrm{~nm})$ scatter. A slow ramp behavior is apparent and it is accentuated by a smoothing procedure of the data (moving average using 25 sequential points in each average) shown in the black line. 


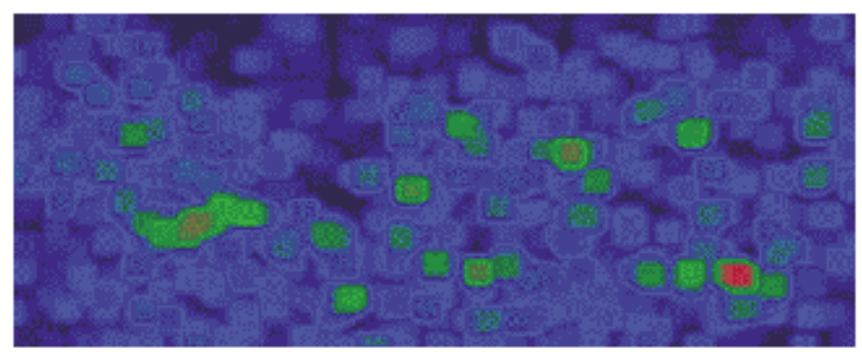

A

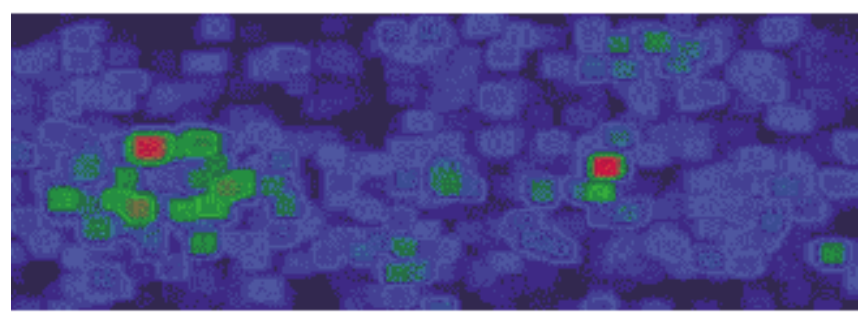

B
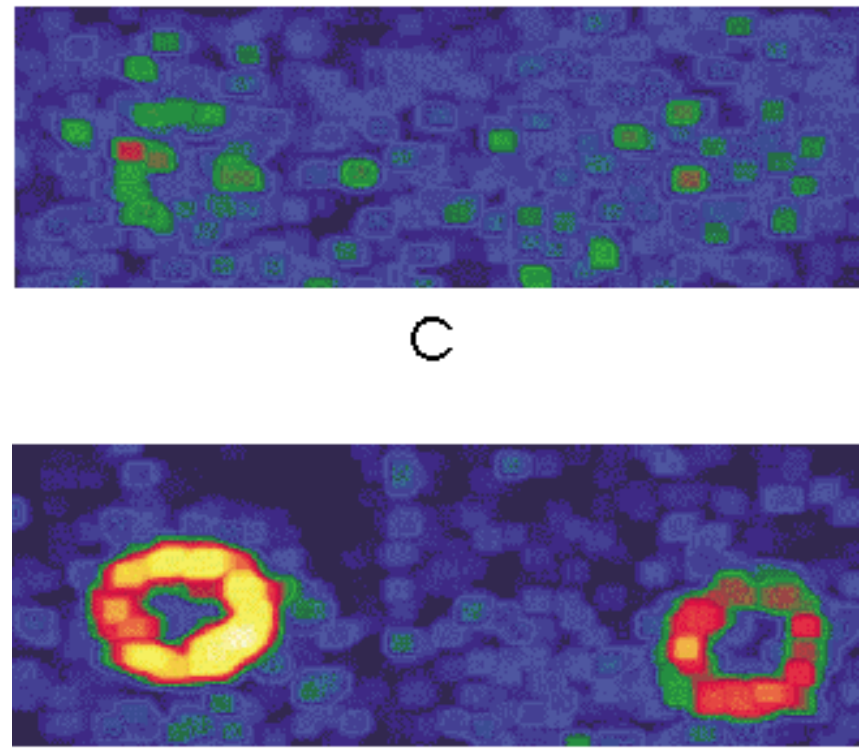

$\mathrm{D}$

Fig. 3A, B, C and D - Sequence of difference frames showing in time/space the evolution of the red and blue scatter at the critical transition before propagation. The difference frames were taken with a $240 \mathrm{msec}$ interval. In the sequence we show the second, the fifth the thirteenth and the nineteenth differences from a original sequence of 19 difference frames, available to reader at the Internet (www.lsi.usp.br/ bioinfo/). The frames were chosen to show the peaks in the red scatter signal. The last frame shows the amplification in both time and space just at the transition to propagating wave. 


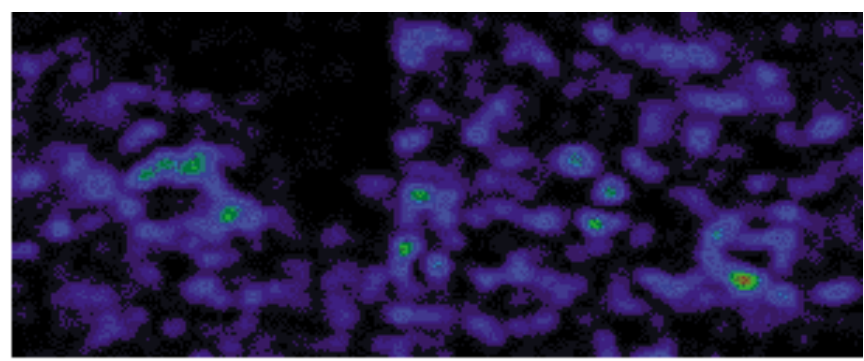

A

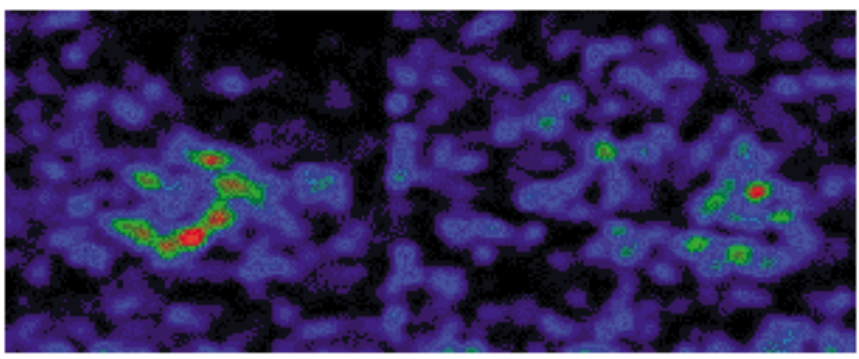

B

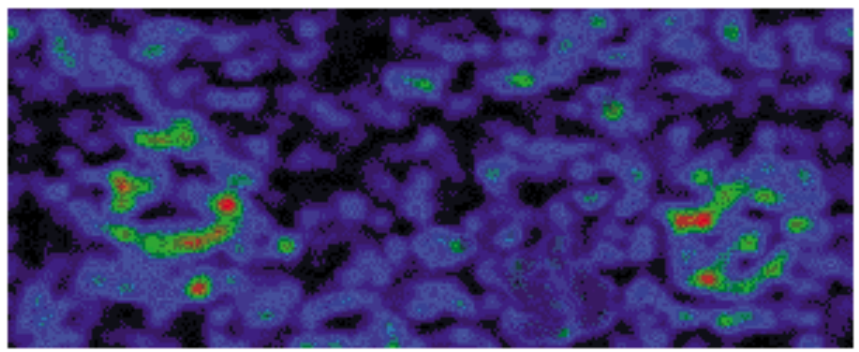

C
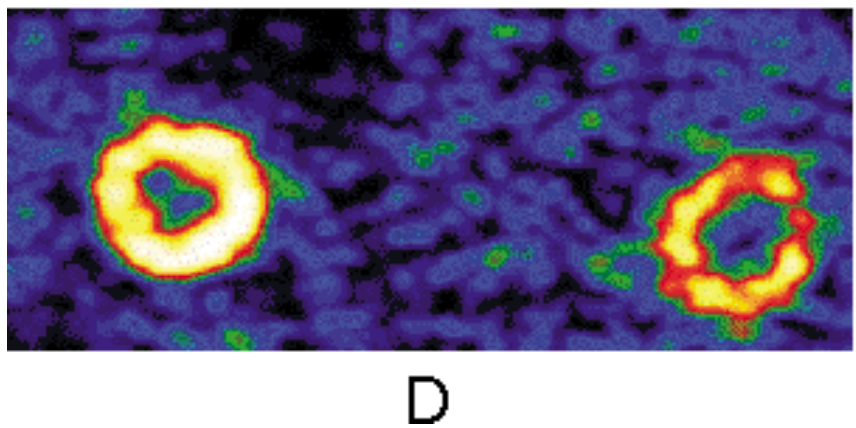

Fig. 4A, B , C and D - From the same original 20 average frames, another sequence of difference frames were taken, using a time interval of 1.5 seconds to show the slow increase in time/space of the blue scatter. 
RSDs was demonstrated in the critical transition from quiescent to excited state in the experiment presented in this paper. We are not aware of a similar detailed demonstration of this phenomenon, predicted by the theory of waves in excitable media. The space resolution (5 microns per pixel) of the difference frames allowed the 2D display of the amplification of fluctuations before propagation. This amplification is not only in time but also in space. The region of maximum brightness (shown in red and yellow at Figures 3 and 4) changes with time and the region involved grows in the interval between stimulus and wave propagation at one particular component of the IOS of the RSDs. The fluctuations were seen inside a region of the stimulated tissue that forms a low dimensional dynamic structure (see Figure 1B, center of red scatter signal). The macroscopic nature of this low dimensional dynamic arrangement shows that the whole system undergoes a transition from quiescent to excited state. Selforganized oscillations in the perineuronal net/membrane cell coat anionic gels (Yoshida et al. 1995) can explain the observed waxing and waning of brightness within the low dimensional optical signal.

The increase in scattered red light that precedes RSDs appeared to follow the electrical field generated at the wave front. In other words, it appears to be to be a measure of glial membrane channel activity (see Hanke et al. 1993 and Fernandes de Lima and Hanke 1997). The slow kinetics, of hundreds of milliseconds for its appearance, agrees with the typical glial membrane depolarization and potassium channels activity (see Hanke et al. 1993 and Fernandes de Lima and Hanke 1997). A much faster rise in scattered light is seen in isolated nerve fibers during an action potential and in the Torpedo electric organ during post-synaptic activity (see, for example, Tasaki 1996, 1999). In both cases, the rise of the intrinsic optical signal proceeds in parallel with the electrophysiological response signal.

A two state physicochemical theory of membrane excitation is as old as the ionic hypothesis of Hodgkin and Huxley (see Abood and Hoss 1976 and Tasaki 1968) and it is also supported by expres- sive experimental data. Ichigi Tasaki work is emblematic of this view of membrane activity. In the early nineties, he proposed that volume phase transition in the cell coat/membrane/protoplasm gels was the mechanism responsible for the excited state of a cell (Tasaki and Byrne 1992, 1994). The interpretation given here about the nature of the scattered light signal that precedes propagation assumes that the extracellular matrix of the inner plexiform layer and the glial membrane external surface are able to undergo volume phase transitions in the same way that ionic gels, axons and fish electric organ (Tasaki 1996, 1999, Tasaki and Byrne 1994).

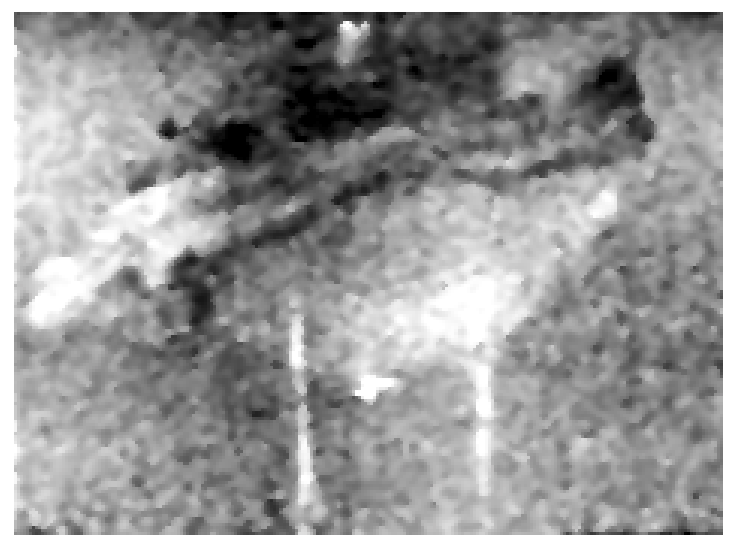

Fig. 5 - Photograph of isolated lens impaled with two tungsten electrodes $1 \mathrm{~mm}$ apart. A red laser beam crosses the lens in midpoint between electrodes. At the equator of the lens parts of the iris are seen. Note that the light beam is not visible within the lens except at the entering and leaving points.

\section{Electrical Field Effects on the Optical Properties of Transparent Tissue}

In Figure 5 the lens is transparent to the light beam except at as the beam enters and leaves it. In these regions, the lens epithelium is actively maintaining electrochemical gradients (the lens characteristic gradient is $125 \mathrm{mEq} / \mathrm{l}$ of potassium inside versus $4.5 \mathrm{mEq} / \mathrm{l}$ outside and $20 \mathrm{mEq} / \mathrm{l}$ sodium inside versus $145 \mathrm{mEq} / \mathrm{l}$ outside and $18 \mathrm{mEq} / \mathrm{l}$ chloride inside versus $110 \mathrm{mEq} / \mathrm{l}$ outside - Cotlier 1981) and promoting the exchange of metabolites and nutrients 


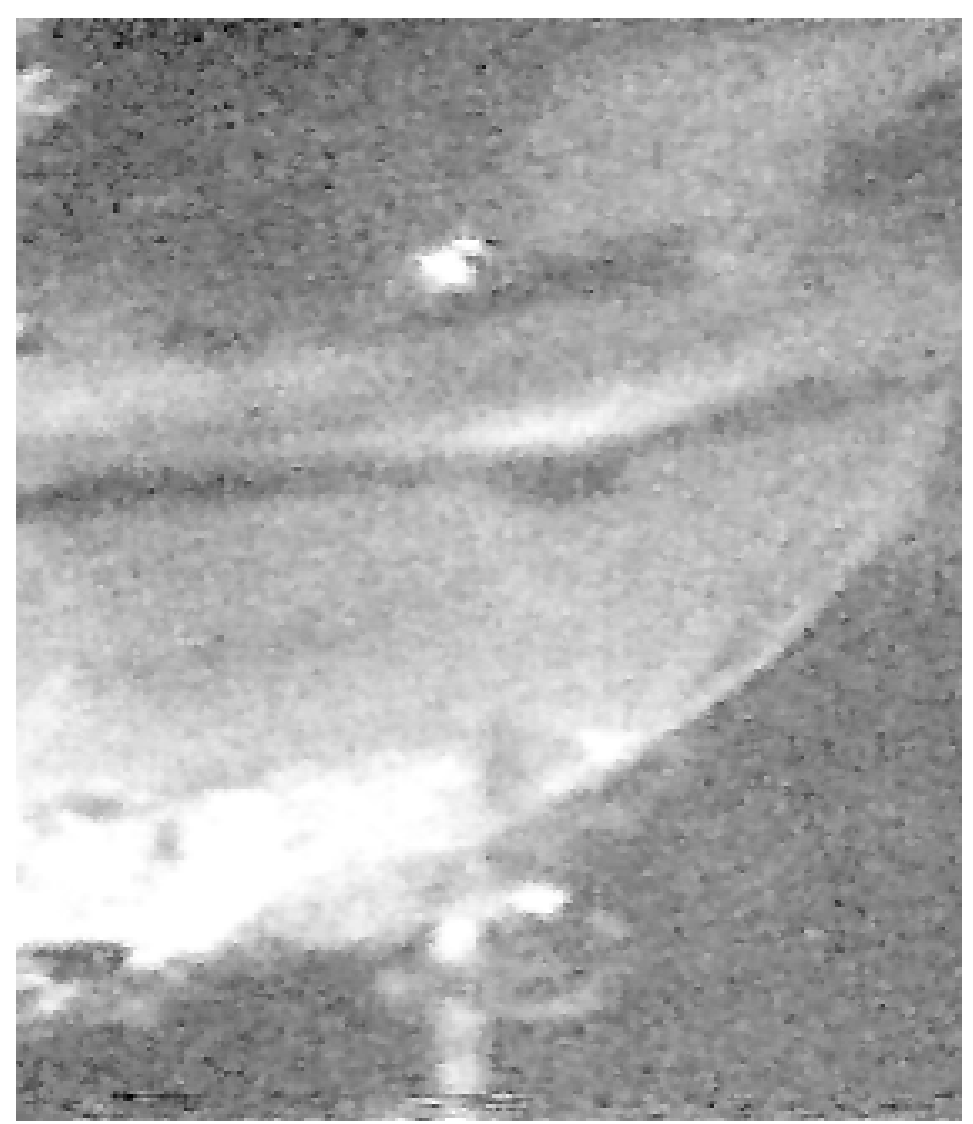

Fig. 6 - Detail of the laser beam touching the tip and shaft of the tungsten electrode inside the lens and leaving the lens below. Between these two points, the tissue is transparent.

between the lens and body. At these highly active regions, a red scatter signal was seen. This signal was not static but shimmering and changing with time.

In Figure 6, the details of the laser touching one electrode tip and leaving the lens bellow is displayed in another photograph. In pilot experiments, we could see that the current flow effects were more prominent close to the cathode. In the following experiments, the laser beam was positioned touching the electrode tip as shown in Figure 6. Figures 7 to 10 show the result of the application of a square pulse of 1.5 second duration and 20 volts intensity. All the four figures were taken from the same sequence of 92 frames acquired from videotape. The whole sequence lasts 3 seconds ( $30 \mathrm{~Hz}$ video frequency). Figure 7 was taken before the pulse was applied, with the background illumination turned off. Figure 8 is set at $90 \mathrm{msec}$ after the beginning of the pulse, and Figure 9 shows the pattern one second after the frame shown in Figure 8. Figure 10 shows the signal at the end of the sequence. Note the changes of the optical properties of the tissue around the electrode tip and at 300 microns from it.

In Figure 9, the maximum scatter is around the electrode where a lesion in the tissue will develop; in consequence, the area loses the transparency to light permanently. The same loss of transparency in the injured tissue is seen in the retina.

The isolated lens maintains a steep electro- 


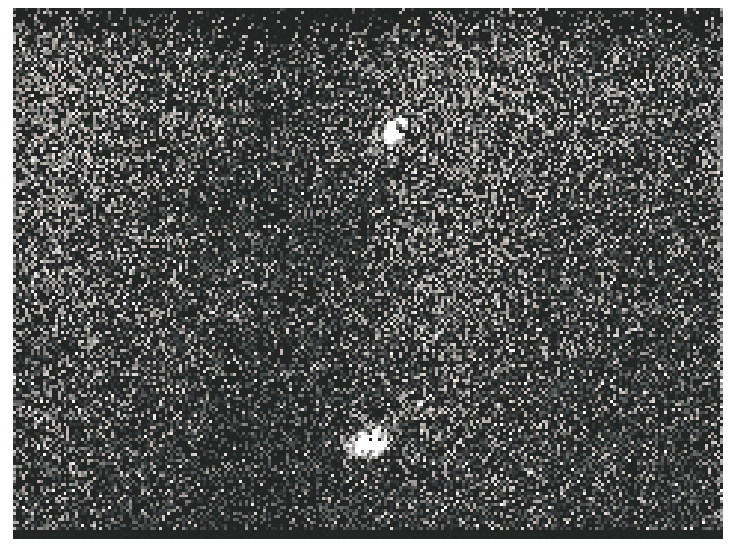

Fig. 7 - Image of crystalline lens without the background illumination, only the laser beam is seen at the electrode tip and leaving the lens. This frame was taken before the application of the current pulse.

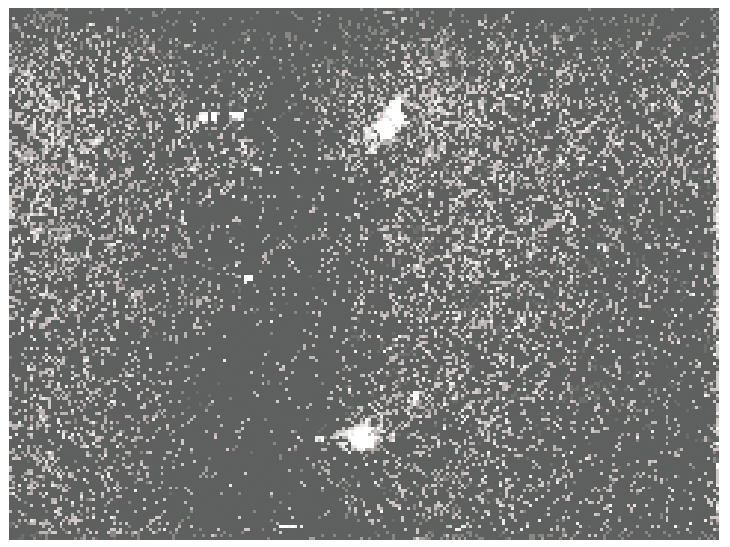

Fig. 8 - Image of the laser beam at the beginning of the pulse, approximately at $90 \mathrm{msec}$ of current flow.

chemical gradient between its core and the bathing solution (see above). It is possible, then, to induce ionic current flow in the lens by challenging this gradient. Touching the external rigid capsule of the lens with glass tube filled with $\mathrm{KCl}$ crystals is an effective way to produce transient inversion of the lens gradient and it was also an effective way of promoting intrinsic optical signals in the lens core (experiment performed in 3 lenses). Although the touch was very gentle, it was possible that mechanical vibrations induced in the lens produced the optical signal. To

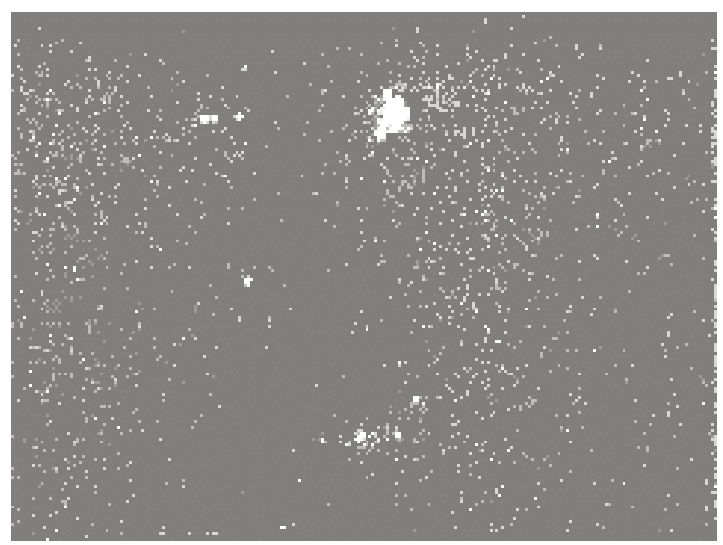

Fig. 9 - Image of the laser beam at approximately one second after the beginning of the pulse.

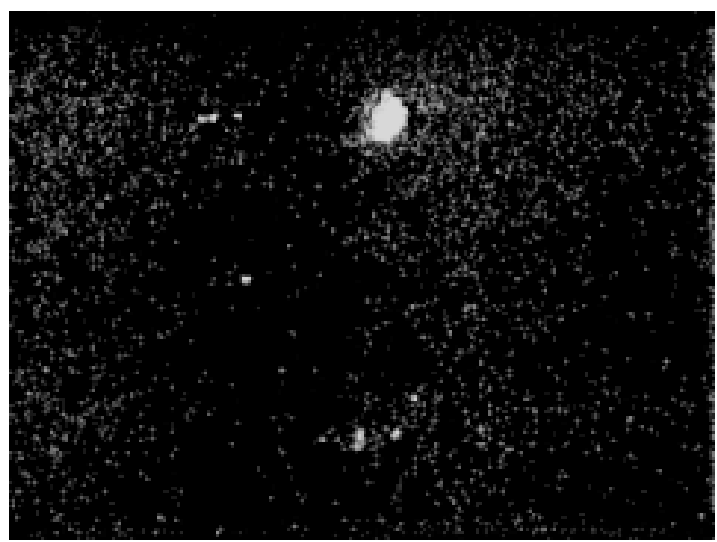

Fig. 10 - Image of the laser beam at the end of the sequence, approximately one second after the end of the pulse. Note that most of the light is scattered around the electrode.

control for that possibility, we substituted the touch by spraying the lens capsule of one additional lens with a $3 \mathrm{M} \mathrm{KCl}$ solution. The same pattern of optical signal was seen in this case. The most economical explanation for the findings is that extracellular ionic flow promotes changes in the optical properties of the lens. Volume phase transitions in the cell coat and extracellular matrix complexes of anionic gels can account for these changes.

The perineuronal net (Celio et al. 1998) of the brain (and probably of the inner plexiform layer of the retina) and the extracellular matrix of the lens 
have a structure much more complex than an anionic gel made of a single polymer. However, three decades of studies with these gels have shown that the volume phase transitions are a general property of these systems and transitions were demonstrated also in more complex systems with heteropolymers (Kokufuta and Matsukawa 1996, Inoue et al. 1997). The experiments performed with the lens were conceived from a particular interpretation about the nature of the IOS of RSDs. They were clear in the demonstration of changes in the optical properties of the tissue, and the tissue response was as expected from the interpretation of early red scatter component of the RSDs IOS. There are structural and functional similarities in the two tissues: in both of them, small tubes with a high surface to volume ratio are normally transparent to light and the extracellular space volume is very small. These similarities were enough for one to guess macroscopic optical signals following membrane ionic transport activity in both tissues.

The lens is a biological preparation very easy to handle and it appears very promising in the study of the role of autowaves in tissue and about the origin of intrinsic optical signals; the only means of interchange between the bulk of the lens and the body is through the coupling via gap junctions (White and Bruzzone 2000) or through the extracellular space via membranes and extracellular matrix interactions. Further studies made in parallel in the two experimental preparations (in vitro retina and lens) are necessary in order to clarify the role of the extracellular matrix in conveying information by conformational changes.

A very interesting fact is that, some of the heteropolymer gels systems can memorize molecular conformation (Alvarez-Lorenzo et al. 2000, Enoki et al. 2000). It is known that the junctional basal laminae of the vertebrate muscle fiber retains information and guides reinnervation of the fiber by the axon, demonstrating an informational role for the matrix. It is possible, then, that conformational changes in the perineuronal net (Celio et al. 1998) can have an informational role being part of the long- range correlations observed in excitation waves propagation.

\section{ACKNOWLEDGEMENTS}

This research received the support from the CAPES/ DAAD PROBRAL program, process 14/94 and a grant from FAPESP 3509-9/94.

\section{RESUMO}

O encéfalo é um meio excitável no qual ondas de excitação se propagam em várias escalas de tempo e espaço. Potenciais de axônios "unidimensionais" (escala de milisegundos) ao longo da membrana axonal e ondas de depressão alastrante (segundos a minutos) nas três dimensões do neurópilo da substância cinzenta (complexo de membranas interagentes) são exemplos de ondas de excitação. Na retina, ondas de excitação têm um sinal óptico intrínseco proeminente (IOS). Este sinal óptico é criado pelo espalhamento da luz e tem componentes diferentes nos extremos azul e vermelho do espectro visível. Pudemos observar a erupcão da onda na retina e medir as mudanças ópticas na transição crítica da quiescência à onda propagada. Os resultados demonstram a presença de flutuações precedendo a propagação e sugerem uma transição de fase. Interpretamos estes resultados baseados em uma extrapolação dos experimentos de Tasaki com potenciais de ação e transições de fase volumétrica em polímeros. Assim, o espalhamento da luz vermelha parece ser uma transição de fase volumétrica na matriz extracelular que seria causada pelas interações entre o revestimento da membrana celular e os complexos extracelulares de carboidratos e proteínas. Se esta hipótese fosse correta, o forçar de um fluxo de corrente extracelular deveria criar um sinal semelhante em outro tecido, desde que tal tecido fosse também transparente à luz e tivesse um espaço extracelular similarmente reduzido. Este tecido controle existe e é a lente cristalina. A exceção dos experimentos confimou as mudanças ópticas. As transições de fase dos polímeros extra-celulares poderia ser uma parte importante das correlações a longa distância encontradas durante a propagação de ondas no sistema nervoso central.

Palavras-chave: sinais ópticos intrínsecos, transição de 
fase volumétrica, polímeros, depressão alastrante, substância cinzenta central, matriz extracelular.

\section{REFERENCES}

Aвood LG ANd Hoss W. 1976. Excitation and conduction in the neuron. In: George Siegel et al. (Eds.) BASIC NEUROCHEMISTRY, Little, Brown and Co., Boston, 1976. p. 103-124.

Alvarez-Lorenzo C, Guney O, Oya T, Sakai Y, Kobaiashi M, Enoki T, Takeoka Y, Ishibashi T, Kuroda K, Tanaka K, Wang GQ, Grosberg AY, Masamune S and Tanaka T. 2000. Polymer gels that memorize elements of molecular conformation. Macromolecules 33(23): 8693-8697.

Brand S and Hanke W. 1996. Temporal delay of onset of retinal spreading depression waves after mechanical stimulation of the tissue. J Brain Res 37(2): 202-203.

Bures J, Buresova O and Krivaneck J. 1984. The mechanism and applications of Leão's spreading depression of electroencephalogram. An Acad Bras Cienc 56(4): 385-400.

Celio MR, Spreafico R, De Biasi S and VitellaroZucCarello L. 1998. Perineuronal nets: past and present. Trends Neurosci 21 (12): 510-515.

Cotlier E. 1981. In: Moses RA (Ed.), Adler's Physiology of the Eye, CV Mosby Co.: St Louis, Toronto, London, pp.277-303.

Enoki T, Tanaka K, Oya T, Takeoka Y, Ito K, Wang GQ, annaka M, Hara K, Du R, Chuang J, Wassermann K, Grossberg AY, Masamune $\mathrm{S}$ AND TANaKa T. 2000. Frustrations in polymer conformation in gels and their minimization through molecular imprinting. Phys Rev Letters 85(23): 5000-5003.

Fernandes de Lima VM and Hanke W. 1996. Long range interactions in the triggering and onset of retinal spreading depression waves. J Brain Res 37: 200201.

Fernandes de Lima VM and Hanke W. 1997. Excitation waves in central gray matter: the retinal spreading depression. Prog Ret Eye Res 16: 657-690.
Fernandes de Lima VM, Golderman M and Hanke W. 1994. Calcium waves in gray matter are due to voltage-sensitive glial membrane channels. Brain Res 663: 77-83.

Goldermann M, Hanke W, Guimarães de Almeida AC and Fernandes de Lima VM. 1998. Observations on the onset and propagation of excitation waves in neural tissue. Int J Bifurc Chaos 8(7): 1541-1549.

Goroleva NA AND Bures J. 1983. Spiral waves of spreading depression in isolated chicken retina. J Neurobiol 14: 353-363.

GouRAs P. 1958. Spreading depression of activity in amphibian retina. Am J Physiol 195: 28-32.

HAKen H. 1977. Synergetics: An Introduction. Springer Verlag: Berlin, Heidelberg, New York.

Hanke W, Fernandes de Lima VM and Schlue WR. 1993. Patch-clamp experiments in the intact retina during spreading depression. In: LeHMENKUELER A, Grotemeyer KH and Tegtmeier F (Eds.), Migraine - Basic mechanisms and treatment. Urban and Schwarzenberg: Munich, pp. 573-582.

Inoue T, Chen GH, Nakamae K and Hoffmann AS. 1997. Temperature sensitivity of a hydrogel network containing different LCST oligomers grafted to the hydrogel backbone. Polymer Gels Networks 5(6): 561-575.

Kokufuta E and Matsukawa S. 1996. Construction of a biochemo-mechanical system using inhomogeneous polyelectrolyte gels with immobilized urease. Berichte der Bunsen-Gesellschaft Phys-Chem Chem Phys 100: 1073-1078.

Martins-Ferreira H and Oliveira-Castro G. 1966. Light scattering changes accompanying spreading depression in isolated chick retina. J Neurophysiol 29: 715-726.

Martins-Ferreira H and Oliveira-Castro G. 1971. Spreading depression in isolated chick retina. Vision Res. Supp 3: 171-184.

TASAKI I. 1968. Nerve excitation, a macromolecular approach. Charles Thomas Pub. Springfield Il.

TASAKI I. 1996. Rapid changes in light-scattering in the prism of TORPEDO electric organ slice associ- 
ated with the production of post-synaptic potentials. Biochem Biophys Res Comm 218: 298-301.

TASAKI I. 1999. Evidence for phase transition in nerve fibers, cells and synapses. Ferroelectrics 220: 305316.

TASAKi I ANd Byrne PM. 1992. Discontinuous volume transitions in ionic gels and their possible involvement in the nerve excitation process. Biopolymers 32: 1019-1023.
TASAKi I AND Byrne PM. 1994. Discontinuous volume transitions induced by Calcium-Sodium ion exchange in anionic gels and their neurobiological implications. Biopolymers 34: 209-215.

White TW ANd BRuzzone R. 2000. Intercellular communication in the eye: clarifying the need for connexin diversity. Brain Res. Rev 32(1): 130-137.

Yoshida R, Ichijo H, Hakuta T and Yamaguchi T. 1995. Self-oscillating swelling and deswelling of polymer gels. Macromol Rapid Commun 16: 305310. 